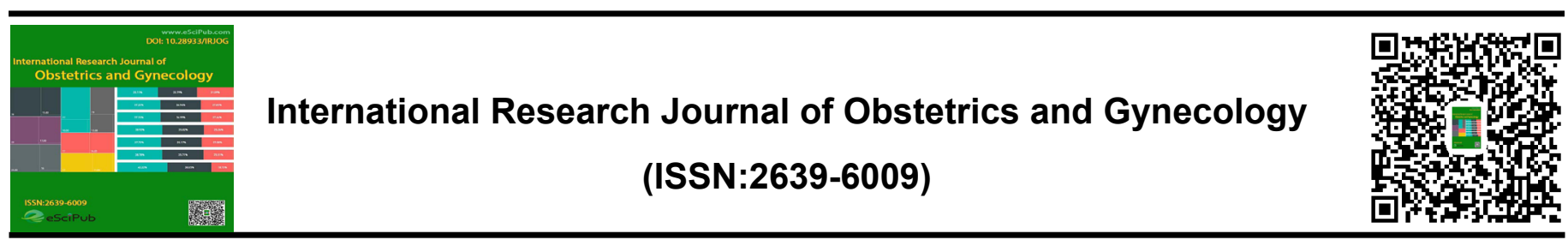

\title{
PROFILE OF PREGNANT WOMEN COLONIZED BY GROUP B Streptococcus SERVED BY THE UNIQUE HEALTH SYSTEM IN A LABORATORY OF MEDIANEIRA / PARANÁ
}

Solange Matias Heinzen*, Isabel Fernandes de Souza, Sheila Caroline Vendrame Maikot, Aline Preve da Silva, Paola Fernanda Fedatto, Ana Carolina Martins Gomes

Higher Education Institute of Foz do Iguaçu (IESFI), Foz do Iguaçu, PR.

\section{ABSTRACT}

Objective: The objective of this study was to determine the prevalence of pregnant colonization by group B Streptococcus (GBS) and to verify whether socioeconomic and demographic conditions are risk factors for colonization by this bacterium. Method: This cross-sectional study included the collection of sociodemographic data through a questionnaire and authorization to access the result of the cultivation of vaginal swabs for the investigation of GBS of 50 women treated at the Unified Health System (SUS) in a laboratory in the municipality of Medianeira, PR, between august and september 2020. Results: The population studied showed a $14 \%$ prevalence of colonization by GBS, within national and world standards. Among the factors analyzed, the only significant and protective association was living with fewer people in the same house, up to two people, reducing the risk of developing a positive culture for GBS by more than 5 times (5.54) when compared to pregnant women who live with more than 3 people in the same residence $(p<0.1$; RR $=0.181$, Cl 90\% 0.040.82 ). There was no association between colonization by GBS with age, skin color, school education, occupation and type of housing, income, fixed partner, parity and gestational symptoms. Conclusion: This study requires greater sampling for statistical strengthening, however it indicates basic data for the creation of GBS disease prevention protocols based on the applied community.

Keywords: Streptococcus agalactiae. Group B Streptococcus (GBS). Vaginal swabs. Maternal colonization. Maternal-fetal diseases.
*Correspondence to Author:

Solange Matias Heinzen

Higher Education Institute of Foz do Iguaçu (IESFI), Foz do Iguaçu, PR.

How to cite this article:

Solange Matias Heinzen*, Isabel Fernandes de Souza, Sheila Caroline Vendrame Maikot, Aline Preve da Silva, Paola Fernanda Fedatto, Ana Carolina Martins Gomes. PROFILE OF PREGNANT WOMEN COLONIZED BY GROUP B Streptococcus SERVED BY THE UNIQUE HEALTH SYSTEM IN A LABORATORY OF MEDIANEIRA I PARANÁ. International Research Journal of Obstetrics and Gynecology, 2021, 4:38

\section{eScîPub}

eSciPub LLC, Houston, TX USA. Website: https://escipub.com/ 


\section{INTRODUCTION}

Streptococcus agalactiae or Streptococcus group B (SGB) from Lancefiel are facultative anaerobic bacteria present in the natural microbiota of the gastrointestinal tract, a place that consists of its main reservoir ${ }^{1}$.

Such bacteria belong to the Streptococcaceae family and are present in the form of grampositive diplococci, and may be in arrangements, in pairs or in chains. They are catalase negative microorganisms, homofermenters, that thrive well in cultures enriched with blood ${ }^{2}$.

Due to the anatomical proximity of the anusvagina, about a third of women present infections of the genitourinary tract in a chronic or intermittent way ${ }^{1,3}$, which can be especially harmful to the mother and fetus during pregnancy ${ }^{4}$ and can cause serious diseases in puerperal women and neonates ${ }^{5}$.

When present in pregnant women, bacteria belonging to the GBS group can cause cystitis and endometritis, which manifest mainly postpartum, with symptoms of abdominal pain, fever and uterine bleeding in the puerperal woman ${ }^{4}$. The baby's chance of premature birth is increased and premature rupture of the membranes (ovular and amniotic) can occur, resulting in intrauterine fetal death and abortion ${ }^{2,5}$. It is also known that, when the mother is colonized by GBS, the newborn has a $50 \%$ risk of being colonized, and is 29 times more likely to develop neonatal sepsis ${ }^{6}$.

A case review carried out by the Centers for Disease Control and Prevention (CDC) in the United States, showed a significant reduction in the incidence of neonatal disease by early-onset GBS when using intrapartum chemoprophylaxis in women with started labor and with amniotic membrane rupture 4 . Thus, between 35 and 37 weeks of gestation, it is recommended to perform the culture test for GBS in pregnant women and follow the treatment protocol to prevent the transmission of GBS to the newborn in positive cases?
Knowing the importance of early diagnosis for the health of the pregnant/postpartum woman and the newborn and, considering that the socioeconomic conditions may be a risk factor for this infection, this study aimed to determine the prevalence of maternal colonization by GBS and to verify association with sociodemographic factors of pregnant women attended by the Unified Health System (SUS) in the municipality of Medianeira, Paraná. This information can contribute to the development of strategies that reduce complications due to GBS infection in the studied population.

\section{METHOD}

This work consisted of an epidemiological, observational and cross-sectional study. To this end, this study was divided into two stages, the first of which was the application of a structured questionnaire to collect socioeconomic and demographic information, followed by the collection of the sample for microbiological culture to check the presence of GBS in pregnant women who had medical request for the exam between 2020 August and September.

This project was approved by the Human Research Ethics Committee (CEP), of the State University of Western Paraná (Unioeste) under CAAE 35293020.1.0000.0107. The ethical principles of privacy, confidentiality, beneficence, non-maleficence, justice and autonomy of the collected data were respected, and data were obtained after agreement and signing the Free and Informed Consent Term (FICT).

The research was conducted in a laboratory, located in the city of Medianeira/PR with formal authorization from the local management. The laboratory has a specific room for the collection of biological material that contains the necessary furniture and personal protective equipment. The collection environment is reserved, ensuring that the patient will have her privacy and discretion guaranteed to the maximum during the period of collection of biological material and also of socioeconomic and demographic data. 
Due to the COVID-19 pandemic of the year 2020, the volume of collections requested fell dramatically, making the sample number of this study for the intended period fall short of that proposed. Given the situation, in the months of August and September 2020, questionnaires were applied and the results of a bacterial culture test for group B Streptococcus of 50 women who were admitted to a laboratory accredited to SUS, in the municipality of Medianeira/PR, were observed. The data can be seen in the subsequent tables.

The sample in this study is a non-probabilistic type with an intentional scale. Pregnant women over 32 weeks of gestation, who perform prenatal care through the public health network, had a prior medical request for GBS culture and were attended to in a clinical analysis laboratory in the city of Medianeira/PR were invited to participate in the study. .

The criteria for inclusion in the study were used: pregnant women over 32 weeks of gestation who perform prenatal care through the public health network, had a medical request to perform a culture for GBS and who accepted to participate in the study by signing the Free and Informed Consent Term (FICT).

Pregnant women who were in the gestational period less than 32 weeks and/or who used antibiotics in the last 10 days and/or were submitted to a gynecological examination 24 hours prior to the collection of vaginal-anal material were excluded from the study.

The collection was performed through one vaginal swab by the responsible professional, the samples were stored in Stuart's transport medium and sent to the support laboratory that prepared the exams and released the technical reports.

Socioeconomic and demographic data were analyzed descriptively. For statistical analysis, a chi-square test $(\mathrm{X} 2)$ was used, with a confidence interval $(\mathrm{Cl})$ of $90 \%$ and considering alpha 0.1 . The Relative Risk (RR) was calculated using the formula: $R R=$ Risk in exposed / Risk in unexposed. Difference of $p=0.1$ was considered significant. The statistical package used for analysis was the GraphPad Prism 8 for MacOS program (V. 8.4.3, GraphPad Software, LLC).

\section{RESULTS}

Fifty pregnant women were tested, among which positive results for GBS culture were observed in 7 women $(14 \%-43$ women had negative bacterial culture for GBS). Due to the low number of samples obtained, adequate statistical strength was not possible.

Globally, women ranged from 16 to 40 years old (median 28 years old); predominantly declared themselves white (45 women declared themselves white; 3 black; 2 others); $58 \%$ of the women evaluated finished high school and $6 \%$ had completed or completed a third degree (1 without study; 17 completed the first degree currently known as elementary school; 29 completed high school or high school; 3 have completed higher education or in progress); $88 \%$ of women are dedicated to home activities (44 women work at home; 6 have outside jobs). With regard to housing, there was a predominance of houses $(96 \%$ - 48 documented residing in houses and only 2 documented residing in an apartment), $66 \%$ of whom owned their own home (33 in their own home and 17 in rented properties) and $84 \%$ of these women live with one or three more people in the residence $(3$ women live alone; 21 with one more person; 21 with two more people; 4 live with three more people; only one lives with more than 4 people in the residence). Regarding family income, $74 \%$ of women declare values of up to 3 minimum wages ( 9 women declare family income between 1 and 2 minimum wages; 28 family income between 2 and 3 minimum wages; 9 family income between 3 and 4 minimum wages; 1 family income between 4 and 5 minimum wages; 3 family income above 5 minimum wages). The minimum wage considered was $R \$ 1,045.00$ according to the Federal Official Gazette Published on: 01/31/2020 | Edition: 22 | Section:

1 | Page: 1 (https://www.in.gov.br/web/dou/- 
/medida-provisoria-n-919-de-30-de-janeiro-de2020-240824899).

Among the women evaluated $90 \%$ had a steady partner (45 with a steady partner; 5 declared they had no partner) and half of the women assessed (50\%) were in their first pregnancy (25 in the first pregnancy; 17 in the second; 8 in the third pregnancy). When questioning preponderant symptoms during pregnancy $40 \%$ reported not having specific symptoms during the process $(n=20), 32 \%$ reported some type of pain (3 reported pain when urinating; 7 pain in the lower abdomen; 6 low back pain) and $8 \%$ reported nausea and heartburn with or without vomiting $(n=4)$

Table 01. Sociodemographic data of pregnant women who underwent colonization by GBS.

\begin{tabular}{llll}
\hline Characteristic & TOTAL & Positive Culture & Negative Culture \\
\hline Age & 3 & & \\
16 to 19 years & 28 & 4 & 2 \\
20 to 29 years & 18 & 2 & 16 \\
30 to 39 years & 1 & 0 & 1
\end{tabular}

\section{Race declaration}

White

Black

Other

\section{Studies}

Without study

Elementary school

\section{1}

High school

Completed higher education or in progress

\section{Occupation}

Outside job

Home work

\section{Neighborhood (allotment)}

Belo Horizonte

Centro

Cidade Alta

Condá

Independência

Ipê

Itaipu

Jd. Irene $(\mathrm{BNH})$

Panorâmico

$\begin{array}{ll}0 & 1 \\ 2 & 15 \\ 5 & 24 \\ 0 & 3\end{array}$

\section{Type of housing}

Apartment

\section{Housing condition}

Rent

Own home

\section{Cohabiting}

$\begin{array}{lll}3 & 0 & 3 \\ 21 & 1 & 20 \\ 21 & 5 & 16 \\ 4 & 1 & 3 \\ 1 & 0 & 1\end{array}$




\section{Family salary}

Between 1 and 2 minimum wages

Between 2 and 3 minimum wages

Between 3 and 4 minimum wages

Between 4 and 5 minimum wages

Above 5 minimum wages

$\begin{array}{lll}9 & 0 & 9 \\ 28 & 4 & 24 \\ 9 & 3 & 6 \\ 1 & 0 & 1 \\ 3 & 0 & 3\end{array}$

Table 02. Marital status, pregnancy and predominant symptoms in the management of pregnant women who underwent colonization by GBS.

\begin{tabular}{llll}
\hline Characteristic & TOTAL & Positive Culture & Negative Culture \\
\hline Marital status & 5 & 1 & 4 \\
No partner & 45 & 6 & 39 \\
Steady partner & & & \\
& 25 & 3 & 22 \\
Pregnancy & 17 & 3 & 14 \\
First pregnancy & 8 & 1 & 7 \\
Second pregnancy & & & \\
Third pregnancy & 20 & 5 & 4 \\
Symptoms of pregnancy & 6 & 2 & 3 \\
No complaints & 3 & 0 & 7 \\
Low back pain & 7 & 0 & 4 \\
Pain when urinating & 4 & 0 & \\
Pain in the lower abdomen & & \\
Nausea and heartburn with or without vomiting & 4 & & \\
\hline
\end{tabular}

Among the factors analyzed, living with fewer than 5 times (5.54) when compared to pregnant people in the same house, up to two people, had women living with more than 3 people in the a protective factor, reducing the risk of same residence $(p<0.1 ; R R=0.181,90 \% \mathrm{Cl}$ developing a positive culture for GBS by more $0.04-0.82$ ).

Table 03. This table presents the result of the statistical calculations and the $R R$ of the given socioeconomic situations in the development of the positive culture test for GBS.

\begin{tabular}{|c|c|c|c|c|c|}
\hline & Positive Culture & $\begin{array}{l}\text { Negative } \\
\text { Culture }\end{array}$ & TOTAL & $p$ value & $\begin{array}{l}\begin{array}{l}\text { RR } \\
(90 \% \text { IC) }\end{array} \\
\end{array}$ \\
\hline \multicolumn{6}{|l|}{ Age } \\
\hline 16 to 30 years & 5 & 29 & 34 & 0,834 & 1,176 \\
\hline$>30$ years & 2 & 14 & 16 & & \\
\hline Total & 7 & 43 & 50 & & \\
\hline \multicolumn{6}{|l|}{ Studies } \\
\hline Without study or elementary school & 2 & 16 & 18 & 0,659 & 0,711 \\
\hline High school or higher education & 5 & 27 & 32 & & \\
\hline Total & 7 & 43 & 50 & & \\
\hline \multicolumn{6}{|l|}{ Occupation } \\
\hline Outside job & 1 & 5 & 6 & 0,841 & 1,222 \\
\hline Home work & 6 & 38 & 44 & & \\
\hline Total & 7 & 43 & 50 & & \\
\hline \multicolumn{6}{|l|}{ Housing condition } \\
\hline Rent & 4 & 13 & 17 & 0,163 & 2,588 \\
\hline Own house & 3 & 30 & 33 & & \\
\hline Total & 7 & 43 & 50 & & \\
\hline
\end{tabular}

IRJOG: https://escipub.com/international-research-journal-of-obstetrics-and-gynecology/ 5 


\section{Conviventes}

Lives alone or with 1 other person

Lives with more than two people

Total
23

20

43 $0,054^{\star}$

$0,181^{*}$

26

50

\section{Family salary}

0,273

0,469
Up to 3 minimum wages

Above 3 minimum wages

Total

4
3
7

33

43

\section{Marital status}

No partner

Fixed partner

Total

1
6
7

4
39

43
5

45

50

\section{Gestation}

First pregnancy

Second or third pregnancy

Total

3
4
7

2
25

25

50

\section{Symptoms of pregnancy}

With complaints

No complaints

Total

$\begin{array}{lll}2 & 24 & 26 \\ 5 & 19 & 24 \\ 7 & 43 & 50\end{array}$

0,684

1,500

0,684

0,750

43

(1)

Among the factors analyzed, living with fewer people in the same house, up to two people, had a protective factor, reducing the risk of developing a positive culture for GBS by more than 5 times (5.54) when compared to pregnant women living with more than 3 people in the same residence $(p<0.1 ; R R=0.181,90 \% \mathrm{Cl}$ $0.04-0.82$ ).

\section{DISCUSSION}

Group B Streptococcus (GBS) is an important cause of infection in pregnant women and their newborns; however, it has been little studied in Brazil. The implementation of rational disease prevention protocols for GBS should be preceded by data collection at the community level, due to variations in maternal colonization by GBS and in disease incidence rates in different populations.

This study shows a prevalence of $14 \%$ of pregnant women colonized by GBS. These data corroborate with previous national studies that present the prevalence of colonization of pregnancies by GBS from 26 to $4.3 \%{ }^{8,9}$. A global prevalence study (Asia, Africa, Europe, America) of pregnant women with GBS, using meta-analysis, estimated values between $22.4 \%$

and $11.1 \%$, with an average of $17.9 \%(95 \% \mathrm{Cl}$ : 16.2 -19.7).

A study carried out in Ribeirão Preto, comparing the epidemiological data of pregnant women colonized by the SGB and treated in two hospitals, with different socioeconomic profiles, found no relation with this factor, which included age, marital status, education, parity, previous abortions, previous cesarean sections, alcohol consumption and smoking, urinary tract infection during pregnancy, use of vaginal creams or antibiotics in the last 3 months ${ }^{10}$. The only socioeconomic factor in our study that showed a significant $R R$ in colonization by GBS in the women in this study, was the protective effect of the smaller contingent of people living in the same residence. We observed that the interaction of up to two people in the same house, reducing the risk of developing a positive culture for GBS more than 5 times (5.54) when compared to pregnant women who live with more than 3 people in the same residence $(p<0$, $1 ; \mathrm{RR}=0.181,90 \% \mathrm{Cl} 0.04-0.82)$.

Regarding parity, the literature presents conflicting data. While some studies point to a higher prevalence of GBS colonization in the first 
pregnancy, others refer to the increase in prevalence after the fifth pregnancy ${ }^{11}$. There are no data in these publications to exclude conflicting factors, making it difficult to interpret the findings. Other populations studied showed no relation to pregnancy ${ }^{11}$. However, our work corroborates the non-relationship between colonization by GBS and the number of pregnancies.

The present study has limitations, mainly to the sample number and population evaluated in a single collection service location, and cannot be extrapolated to the general population. However, this information is important for the establishment of a care protocol with intrapartum antibiotic therapy as recommended by the CDC.

\section{CONCLUSION}

The prevalence found in the pregnant women evaluated in this study is between the national and world average as expected. It is necessary to increase the amount of sample to increase the statistical power and perform a more detailed analysis of other interfering factors that may be related to the protocol and selection of pregnant women who must undergo prophylactic intrapartum antibiotic therapy.

\section{References}

1. Trabulsi LR, Alterthum F. Microbiologia. 50 ed. São Paulo: Atheneu; 2015. 920 p.

2. Bastos AN, Bastos RV, Dias VC, Bastos LQ de A, Souza RC de, Bastos VQ de A. Streptococcus agalactiae em gestantes: incidência em laboratório clínico de Juiz de Fora (MG) - 2007 a 2009. HU Rev Juíz Fora. 2012;38(3 e 4):129-34.

3. Costa NDVL, De Carvalho M, Pone SM, Saint Clair G. Gestantes colonizadas pelo Streptococcus do grupo B e seus recémnascidos: Análise crítica da conduta adotada no Instituto Fernandes Figueira, Fundação Oswaldo Cruz. Rev Paul Pediatr. 2010;28(2):155-61.

4. Beraldo C, Brito ASJ de, Saridakis HO, Matsuo T. Prevalência da colonização vaginal e anorretal por Estreptococo do grupo B em gestantes do terceiro trimestre. Rev Bras Ginecol Obs [Internet]. 2004;26(7):543-9. Available from: http://www.scielo.br/scielo.php?script=sci_arttext \&pid=S0100-72032004000700006

5. Ceballos CA, Loaiza N, Romero J, Ospina M, Vásquez EM. Caracterización de las gestantes tamizadas para Streptococcus agalactiae y su relación con sepsis neonatal temprana, en la Clínica del Prado de Medellín (Colombia), año 2010. Infectio [Internet]. 2014;18(2):66-71. Available from: http://dx.doi.org/10.1016/j.infect.2013.12.002

6. Nomura M. Colonização materna e neonatal por Estreptococo do grupo B em gestantes com trabalho de parto prematuro e/ou ruptura prematura pré-termo de membranas [Internet]. Universidade Estadual de Campinas - UNICAMP; $2004 . \quad$ Available from: http://www.bibliotecadigital.unicamp.br/document /?code =vtls000341767

7. Gallo CBG. A importância do diagnóstico em gestantes colonizadas pelo Streptococcus do grupo beta na prevenção da doença neonatal. São José do Rio Preto; 2015.

8. Benchetrit LC, Fracalanzza SEL, Peregrino $\mathrm{H}$, Camelo AA, Sanches LA. Carriage of Streptococcus agalactiae in women and neonates and distribution of serological types: A study in Brazil. J Clin Microbiol. 1982;15(5):787-90.

9. Martins BL, Jacob T, Oliveira C De. Prevalência de Streptococcus agalactiae em secreção vaginal de gestantes atendidas em um laboratório de análises clínicas do interior do estado de São Paulo. Salusvita. 2017;36(3):695-707.

10. Zusman AS, Baltimore RS, Fonseca SNS. Prevalence of maternal group B Streptococcal colonization and related risk factors in a Brazilian population. Brazilian J Infect Dis. 2006;10(4):2426.

11. Szylit NA, Malburg FL, Piccinato $C$ de A, Ferreira LA de P, Podgaec S, Zlotnik E. Prevalência de colonização retovaginal por Estreptococo do grupo B em gestantes de programa de atendimento pré-natal de instituição de saúde. Einstein. 2020;18(2):1-6. 